\title{
FORMULASI MULTISENSORY DALAM PEMBELAJARAN TEMATIK
}

\author{
Mohamad Maulidin Alif Utama \\ STAI Asy-Syukriyyah Tangerang \\ mohamad.maulidin93@gmail.com
}

\begin{abstract}
Learning materials that are still abstract is one of the obstacles for teachers in understanding students. Specific thematic learning, it is necessary learning that not only keeps students active in learning activities, but also students can understand the intent and purpose of the theme they are learning, the students' understanding can be improved through the model Multisensory learning.Multisensory learning is basically a learning that involves a variety of sensory stimuli including hearing, sight, touch, and sometimes also smell and taste. Multisensory learning models involve a variety of visual aids including IT-based media in support of its application process. The use of visual images, interactive video that is broadcast through the projector can certainly stimulate the student's sensory to the material being studied. Multisensory learning in practice is a learning that for learning materials that are abstract into concrete material. Therefore, the application of multisensory learning needs to involve a variety of critical inquiry activities conducted by students on the various realities of everyday life. for example, when teaching science on food chains, this material will be more easily understood by the child if the child is invited to directly watch the process of occurrence of the food chain in everyday life or at least watch the video showing the concept of the chain of food.The linkage between the multisensory learning model and the thematic learning lies in the process of implementation. The combination of sensory devices in multisensory learning is appropriate when applied to thematic learning in recognizing the material attributed to reallife everyday. Thematic learning uses many teaching aids and sometimes uses the senses that students have.
\end{abstract}

Keyword: Thematic Learning, Multisensory learning

\section{PENDAHULUAN}

Pembelajaran dalam konteks kurikulum 2013 diorientasikan agar siswa mengembangkan sikap, keterampilan dan pengetahuan. Berkaitan dengan orientasi tersebut, proses pembelajaran pada kurikulum 2013 harus dilakukan melalui pembelajran yang aktif dan kreatif sehingga siswa pun akan berkembang kemampuan berpikir kritis dan terampil berkomunikasi serta berkembang pula kreativitasnya.

Guna mewujudkan pembelajaran yang demikian, minimalnya ada lima tahap yang harus dikembangkan guru pada pembelajaran kurikulum 2013, kelima tahap tersebut diantaranya; melakukan observasi dengan menggunakan sains, mengembangkan kemampuan bertanya atau intellectual curiously, kemampuan berpikirm bereksperimen, kemudian komunikasi.

Sejalan dengan kelima tahapan tersebut, minimalnya ada 5 model pembelajaran yang menjadi model inti dalam pembelajaran kurikulum 2013, yaitu model proses saintifik, model integrative berdiferensiasi, model multiliterasi, model kooperatif dan model multisensori. 
Diantara kelima model tersebut, yang akan peneliti fokuskan disini adalah model pembelajaran multisensori.

Model pembelajaran multisensory melibatkan berbagai alat peraga termasuk media berbasis IT dalam mendukung proses penerapannya. Penggunaan visual gambar, video interaktif yang ditayangkan melalui proyektor tentu dapat merangsang sensori siswa terhadap materi yang dipelajari. Namun, permasalahan yang kemudian muncul adalah kendala guru dalam menerapkan model pembelajaran multisensory tanpa menggunakan IT. Itu berarti dibutuhkan kreatifitas guru dalam penerapannya.

Keunikan dan daya tarik pembelajaran multisensori adalah dari segi keterlibatan berbagai alat sensori siswa, tidak hanya melibatkan indra penglihatan dan pendegaran saja tetapi juga berbagai indra lainnya akan terlibat seperti indra pengecapan, peraba, penciuman bahkan gerak. Melalui keterlibatan berbagai indra ini, pembelajaran menjadi bermakna, menarik perhatian, mudah dipahami dan lebih lama tertanam dalam ingatan. Sehingga dalam penerapannya guru menggunakan fasilitas dan media yang ada dan mampu membangkitkan berbagai alat sensori siswa.

Abidin menambahkan bahwa pembelajaran multisensory sangat bertalian dengan konsep belajar yang ditawarkan Glaser. ${ }^{1}$ Glaser mengemukakan bahwa terdapat beberapa gaya belajar dan hasil belajar yang diperoleh dengan menggunakan gaya tersebut. Menurutnya penguasaan berbagai pengetahuan bergantung pada aktivitas belajar yang dilakukan seseorang. Prinsip belajar yang dikemukakan Glaser menyebutkan bahwa kita belajara 10\% dari yang kita baca, 20\% dari yang kita dengar, 30\% dari yang kita lihat, 50\% dari yang kita dengar dan lihat, $70 \%$ dari yang kita diskusikan dengan orang lain, $80 \%$ dari yang kita alami sendiri, dan 95\% dari yang kita ajarakan kepada orang lain.

Pada dasarnya pembelajaran multisensory sangat cocok bagi Madrasah ibtidaiyah karena di madrasah ibtidaiyah menggunakan pembelajaran tematik. Penulis disini akan meformulasikan pembelajaran multisensori dengan pembelajaran tematik.

\section{METODE PENELITIAN}

Tulisan ini merupakan hasil penelitian kepustakaan (library research). Jenis penelitian kepustakaan merupakan penelitian yang mengandalkan data-data yang hampir sepenuhnya dari kepustakaan atau literatur, baik itu dalam bentuk fisik maupun digital. Penelitian ini lebih

\footnotetext{
1 Yunus Abidin. 2016. Desain Sistem Pembelajaran Dalam Konteks Kurikulum 2013. (Bandung : PT Refika Aditama) h. 112
} 
popular dikenal dengan penelitian kualitatif deskriptif kepustakaan atau penelitian bibliografis, dan juga dapat diistilahkan Non Reaktif yang sepenuhnya menggunakan data-data yang bersifat teoritis dan dokumentasi yang ada di perpustakaan

Peneliti memperoleh data dari hasil studi kepustakaan dari berbagai literatur buku, jurnal, karya ilmiah, dan juga dokumen-dokumen lain yang mengkaji terkait Formulasi Multisensory dalam Pembelajaran Tematik, baik secara umum maupun secara khusus.

\section{PEMBAHASAN}

Pembelajaran multisensory pada dasarnya merupakan pembelajaran yang dilaksanakan dengan melibatkan berbagai stimulasi indra meliputi pendengaran, penglihatan, sentuhan, dan terkadang juga penciuman dan pengecapan. Hal ini tentu saja berbeda dengan pembelajaran biasanya yang hanya melibatkan satu indra saja misalnya pendengaran. Melalui berbagai stimulasi ini diharapkan proses pemerolehan informasi tidaknya hanya bersifat satu sumber tetapi dari berbagai sumber.

Blackwood mendefinisikan pembelajaran multisensory sebagai sisstem pembelajaran yang melibatkan penggunaan beragam alat peraga, objek belajar, alat interaktif, klip video, drama, seni, music, latar belakang tematik, makanan, air, bau, dan elemen kreatif lainnya yang merangsang persepsi sensorik. ${ }^{2}$ Berbagai insrumen pembelajaran tersebut selanjutnya digunakan sebagai alat stimulasi bagi siswa agar siswa mampu memberikan respons sehingga akan terbangun perhatian, pemahaman dan retensi.

Abidin menambahkan bahwa pembelajaran multisensory sangat bertalian dengan konsep belajar yang ditawarkan Glaser. ${ }^{3}$ Glaser mengemukakan bahwa terdapat beberapa gaya belajar dan hasil belajar yang diperoleh dengan menggunakan gaya tersebut. Menurutnya penguasaan berbagai pengetahuan bergantung pada aktivitas belajar yang dilakukan seseorang. Prinsip belajar yang dikemukakan Glaser menyebutkan bahwa kita belajara 10\% dari yang kita baca, 20\% dari yang kita dengar, 30\% dari yang kita lihat, 50\% dari yang kita dengar dan lihat, $70 \%$ dari yang kita diskusikan dengan orang lain, $80 \%$ dari yang kita alami sendiri, dan 95\% dari yang kita ajarakan kepada orang lain.

Prinsip belajar Glaser tersebut jika dicermati dapat menjadi acuan bagi para pendidik bahwa pembelajaran tidak berfokus pada membaca, mendengarkan dan menulis saja, tetapi

\footnotetext{
2 Blackwood, Rick. 2008. The Power Of Multisensory Preaching and Teaching. (Michigan : Zondervan) h. 14

${ }^{3}$ Yunus Abidin. 2016. Desain Sistem Pembelajaran Dalam Konteks Kurikulum 2013. (Bandung : PT Refika Aditama.) h.112
} 
juga pengalaman pribadi yang dialami peserta didik dalam pembelajaran. melalui pengalaman itulah diharapkan peserta didik dapat berbagi pengalaman yang nantinya dapat didiskusikan serta saling bertukar pikiran antara siswa satu dengan yang lainnya. Selain itu, melalui pengalaman pribadi peserta didik akan lebih memahami materi dalam pembelajaran sehingga pemahaman tersebut akan menjadi modal baginya untuk mengajarkannya pada orang lain.

Gaya belajar yang dikemukakan Glaser tersebut mendasari munculnya pembelajaran multisensory. Bisa dikatakan, pembelajaran multisensory merupakan pendekatan yang mengharapkan siswa mampu menemukan ilmu pengetahuan sendiri melalui pengalaman pribadi dalam hal mencari dan memecahkan permasalahan kehidupan nyata dilapangan. Pengalaman yang diperoleh tersebut diharapkan siswa lebih jauh mampu memberikan informasi tersebut kepada teman-temannya.

Selanjutnya Abidin menjelaskan bahwa penerapan pembelajaran multisensory juga didasarkan pada asumsi bahwa siswa akan belajar dengan gaya yang berbeda. ${ }^{4}$ Ada sebgian siswa berhasil dengan mengoptimalkan indra pendengarannya, ada juga yang menggunakan indra penglihatannya, dan banyak pula siswa yang berhasil belajar karena terjalin komunikasi yang efektif dengan gurunya. Sejalan dengan gaya belajar siswa yang beragam, itu berarti guru yang menerapkan pembelajaran multisensory harus sensitive terhadap gaya belajar siswanya. Guru harus mamapu mengkondisikan siswa yang memiliki gaya belajar auditoris, visualis, kinestetis atau interaktif.

Pembelajaran multisensori dalam prakteknya merupakan pembelajaran yang dikreasikan agar materi pembelajaran yang bersifat abstrak menjadi materi yang bersifat kongkret. Untuk itu, penerapan pembelajaran multisensory ini perlu melibatkan berbagai aktivitas inkuiri kritis yang dilakukan siswa pada berbagai kenyataan kehidupan sehari-hari. sebagai contoh, ketika mengajarkan IPA tentang rantai makanan, materi ini akan lebih mudah dipahami anak jika anak diajak secara langsung menyaksikan proses terjadinya rantai makanan dalam kehidupan sehari-hari atau minimal menyaksikan tayangan video yang menunjukkan konsep rantai makan.

Menurut Baines pengalaman belajar secara langsung tersebut diyakini dapat meningkatkan pemahaman siswa. ${ }^{5}$ Hal ini diebabkan oleh kenyataan bahwa ketika siswa melakukan pembelajaran melalui proses mengalami, ia akan menggunakan berbagai indranya.

\footnotetext{
${ }^{4}$ Yunus Abidin. 2016. Desain Sistem Pembelajaran Dalam Konteks Kurikulum 2013. (Bandung : PT Refika Aditama) h.120

${ }^{5}$ Slekar, T. S., Lachance, A., Klein, B. S., \& Klein, K. W. 2003. The environmental thematic methods block: A model for technology immersion. Contemporary Issues in Technology and Teacher Education. h. 16
} 
Melalui keterlibatan berbagai indra ini pembelajaran menjadi bermakna, menrik perhatian, mudah dipahami dan lebih tertanam dalam ingatan.

Penerapan model pembelajaran multisensory dapat dilaksanakan melalui beberapa tahapan atau fase berikut:

1. Prapembelajaran, tahapan ini merupakan kegiatan yang dilakukan oleh guru sebelum pembelajaran inti dimulai. Guru mengkondisikan kelas, memotivasi siwa, melibatkan siswa dengan hal yang akan diteliti, mengorgnisasi siswa, dan menjelaskan prosedur pembelajaran.

2. Fase 1 : membuat pertanyaan dan mengujinya, tahap ini siswa diperkenalkan dengan masalah apa yang akan diteliti. Sisa diminta membuat pertanyaan dan kemudian menguji kelayakan dan kelogisan pertanyaan tersebut,

3. Fase 2 : merumuskan hipotesis, siswa belajar merumuskan hipotesis atau jawaban sementara atas rumusan masalah yang telah diajukannya pada tahap sebelummnya dengan mengoptimalkan apa yang telah mereka ketahui.

4. Fase 3 : penelitian berbasis multisensory, melaksanakan kegiatan observasi atau penelitian sederhana.

5. Fase 4 : mengolah dan menganalisis data, tugas guru dalam tahap ini membimbing siswa mengolah dan menganalisis data dan jika diperlukan, guru memberikan gambaran model pengolahan dan penganalisian data yang benar.

6. Fase 5 : menguji hipotesis, siswa membuat pemaknaan proses dan hasil penelitaian yang telah dilaksanakannya. Tugas guru adalah mendorong siswa untuk mengembangkan kemampuan berpikir kritis, evaluative dan kretif.

7. Fase 6: membuat kesimpulan, siswa dengan dibantu guru

8. Fase 7: menyajikan hasil, guru melakukan penilaian atas performa atau produk yang dihasilkan siswa

9. Pascapembelajaran, guru membahas kembali masalah pesta membandingkan antara solusi satu dengan yang lain dari hasil pemikiran siswa dengan solusi secara teoritis yang telah ada.

Demikianlah gambaran model pembelajaran multisensory. Model ini tentunya dapat digunakan dalam berbagai mata pelajaran, khususnya pada pembelajaran tematik dalam kurikulum 2013.

Pembelajaran tematik merupakan pendekatan dalam pembelajaran yang cara sengaja mengaitkan beberapa aspek baik secara indra mata pelajaran maupun antar mata pelajaran. Adanya pemaduan itu siswa akan memperoleh pengetahuan dan keterampilan secara utuh sehingga pembelajaran menjadi bermakna bagi siswa (Depdiknas, 2006). Kovalik and Associates mengemukakan bahwa "ITI (Integrated Thematic Instruction) is a systemic model 
based on current brain research to guide comprehensive schoolwide reform". ${ }^{6}$ Pembelajaran tematik merupakan model yang tersusun berdasarkan riset pemikiran sebagai panduan pembaharuan sekolah secara menyeluruh.

Dixon dan Collins mengemukakan pembelajaran tematik adalah suatu pembelajaran yang melibatkan beberapa bidang studi untuk memeberikan pengalaman bermakna kepada siswa dengan mengaitkan sebuah tema (Dixon\& Collins, 1991: 7). hal ini berarti pembelajaran tematik yang dilkaukan sesuai kurikulum 2013 adalah pembelajaran dengan tema tertentu yang mengaitkan tidak hanya intra dan antar mata pelajaran tetapi juga keterpaduan pembelajaran antar jenjang kelas.

Pembelajaran tematik adalah suatu model terapan pembelajaran terpadu yang mengintegrasikan beberapa mata pelajaran dalam satu kesatuan yang terikat oleh tema. Menurut Slekar (2003:128-145) pembelajaran tematik merupakan suatu usaha memadukan pengetahuan secara komprehensif dan terintegrasi. Pembelajaran terpadu di sekolah dasar membantu mengembangkan pemahaman siswa yang berakibat siswa menjadi lebih terlibat dalam pembelajaran. Glenn (2009:1-10) menambahkan bahwa pembelajaran tematik adalah salah satu pendekatan pembelajaran holistic. Pembelajaran holistic mengandung dua tujuan yaitu menghasilkan pembelajaran bermakna yang memaksimalkan koknitif otak kiri yang dicapai melalui pengembangan keahlian akademis dan teknis, dan pembelajaran yang bermakna menggunakan otak kanan melaui pengembangan social dan ketrampilan nilai Elemen utama pembelajaran holistic adalah keterhubungan antara pengalaman dan realitas dan pembelajaran yang harmoni dengan alam.

Pembelajaran tematik pada kurikulum 2013 menggunakan pendekatan saintifik, artinya proses pembelajaran pada kurikulum 2006 yang semula terfokus pada eksplorasi, elaborasi dan konfirmasi menjadi kegiatan mengamati, menanya, menlar, mencoba, dan mengkomunikasikan (kemendikbud , 2013). Tujuan dari beberaapa proses pembelajaran saintifik sama, yaitu menekankan bahwa belajar tidak hanya terjadi diruang kelas, tetapi juga dilingkungan sekolah dan masyarakat. Artinya proses belajar siswa pada pembelajaran tematik diarahkan untuk terlibat langsung dengan lingkungan yang ada disekitarnya, dengan cara melihat, meraba, merasa, membau, dan mendengar atau pembelajaran yang melibatkan seluruh panca indera siswa, sehingga pembelajaran lebih bermakna. Keterkaitan antara model pembelajaran

\footnotetext{
${ }^{6}$ Kovalik, S \& Associates. 2001. Quastion and Answer About ITI (Integrated Thematic Instruction). (Cvington: Books Educators, Inc) h. 1
} 
multisensory dengan pembelajaran tematik terletak pada proses pelaksanaannya. Perpaduan alat indra pada pembbelajaran multisensory sangatlah sesuai jika diterapkan pada pembelajaran tematik dalam mengenal materi yang dikaitkan pada keidupan nyata sehari-hari

\section{KESIMPULAN}

Pembelajaran multisensory pada dasarnya merupakan pembelajaran yang dilaksanakan dengan melibatkan berbagai stimulasi indra meliputi pendengaran, penglihatan, sentuhan, dan terkadang juga penciuman dan pengecapan. Pembelajaran tematik pada kurikulum 2013 menggunakan pendekatan saintifik, artinya proses pembelajaran pada kurikulum 2006 yang semula terfokus pada eksplorasi, elaborasi dan konfirmasi menjadi kegiatan mengamati, menanya, menlar, mencoba, dan mengkomunikasikan didalam melaksanakan pembelajaran tematik membutuhkan model multisensory karena sangatlah sesuai jika diterapkan pada pembelajaran tematik dalam mengenal materi yang dikaitkan pada keidupan nyata sehari-hari serta pembelajaran tematik menggunakan banyak alat peraga dan terkadang menggunakan indra yang dimiliki oleh siswa.

\section{DAFTAR PUSTAKA}

Blackwood, Rick. 2008. The Power Of Multisensory Preaching and Teaching. Michigan : Zondervan

Dixon \& Colins. 1991. Integrated Learning stage 3. Australia: Bookshelf Kovalik, S \& Associates. 2001. Quastion and Answer About ITI (Integrated Thematic Instruction). (Cvington: Books Educators, Inc).

Glenn, C. E. 2009.The Holistic Curriculum: Addressing the Fundamental Needs of the Whole Child in a Diverse and Global Society.National Forum of Multicultural Issues Journal. Vol. 6 No. 2.

Sisdiknas, 2012. Struktur Kurikulum 2013, Online: http://www.kemdiknas.go.id

Slekar, T. S., Lachance, A., Klein, B. S., \& Klein, K. W. 2003. The environmental thematic methods block: A model for technology immersion. Contemporary Issues in Technology and Teacher Education,

Yunus Abidin. 2016. Desain Sistem Pembelajaran Dalam Konteks Kurikulum 2013. Bandung: PT Refika Aditama 